|| ISSN(online): 2589-8698 || ISSN(print): 2589-868X ||

International Journal of Medical and Biomedical Studies

Available Online at www.ijmbs.info

NLM (National Library of Medicine ID: 101738825)

Index Copernicus Value 2019: 79.34

Original Research Article

Volume 5, Issue 1; January: 2021; Page No. 140-142

\title{
TO DETERMINE RELATION OF SYMPTOM DURATION IN OUTCOME OF CTS
}

\section{Dr. Amit Maheshwari}

Associate Professor, Dept. of Medicine, Amaltas Institute of Medical Sciences, Dewas, M.P.

\author{
Article Info: Received 03 December 2020; Accepted 04 January 2021 \\ DOI: https://doi.org/10.32553/ijmbs.v5i1.1653 \\ Corresponding author: Dr. Amit Maheshwari \\ Conflict of interest: No conflict of interest.
}

\begin{abstract}
Background \& Method: The study was conducted at the neurology Department of Amaltas Institute of Medical Sciences, Dewas, M.P. In our laboratory, the hands are evaluated for CTS using standard techniques with Nicolet Viking IV (ver12). The skin temperature of the body part, under evaluation, is measured using a probe connected to the machine and is maintained at 310c using a commercial hot air blower.

Result: The number of symptomatic hands was more in females (73 vs. 27\%) and persons with high BMI (61.5 vs. 38.5 ); $27.7 \%$ of the hands belonged to the persons having concomitant medical issues. Female gender showed slightly higher odds (OR 1.2, CI 0.5-2.6, two-tailed $\mathrm{p}=0.5$ ) for remission on medical therapy. The median duration of symptoms of our study population was12 months (mean $24.16 \pm 28.93$ months). We had 40 patients having CTS in bilateral hands ( $\mathrm{n}=80$ hands), while 50 patients had unilateral hand symptoms $(n=50$ hands). Forty-one $(31.5 \%)$ hands were symptomatic for 10 months or less (median 6 months) while remaining 89 hands were symptomatic for longer than 10 months (median 24 months). Shorter duration of the symptoms, at presentation, had significant higher odds of spontaneous remission (OR 9.47 CI 3.8-23.1, twotailed $\mathrm{p}=<0.0001)$.
\end{abstract}

Conclusion: In conclusion, it seems reasonable to treat subjects of CTS, conservatively for first ten months after symptom onset, more so when they have four or more out of the seven favorable factors.

Keywords: Symptom, CTS, MMA \& SDL.

\section{Introduction}

Carpal tunnel syndrome (CTS) is an entrapment neuropathy caused by compression of the median nerve as it travels through the wrist's carpal tunnel. Median nerve compression. It is the most common nerve entrapment neuropathy, accounting for $90 \%$ of all neuropathies. Early symptoms of carpal tunnel syndrome include pain, numbness, and paresthesias.

Pain also can radiate up the affected arm. With further progression, hand weakness, decreased fine motor coordination, clumsiness, and thenar atrophy can occur ${ }^{[1]}$. Patients can be diagnosed quickly and respond well to treatment but the best means of integrating clinical, functional, and anatomical information for selecting treatment choices have not yet been identified ${ }^{[2]}$.

The treatment of CTS ranges from conservative management to carpal tunnel release. The conservative care includes splinting, vitamin B6, nonsteroidal antiinflammatory agents, and local corticosteroid injections. The options for CTS release can be standard open carpal ligament release, limited access open release, limited access device-assisted release, and two-port and single-port endoscopic release ${ }^{[3]}$. Endoscopic release results in decreased postoperative pain, reduced scar length, and early return to work.

\section{Material \& Method}

The study was conducted at the neurology Department of Amaltas Institute of Medical Sciences, Dewas, M.P from August 2018 to September 2020. In our laboratory, the hands are evaluated for CTS using standard techniques ${ }^{[4]}$ with Nicolet Viking IV (ver12). The skin temperature of the body part, under evaluation, is measured using a probe connected to the machine and is maintained at 310c using a commercial hot air blower. The median motor conductions are performed with surface disk electrodes applied over abductor pollicisbrevis, and distal latency (MDL) is measured over a distance of $8 \mathrm{~cm}$. The baseline to the negative amplitude of the compound muscle action potential (MMA) is measured. The median sensory nerve is examined antidromically using ring electrodes applied to the middle finger. The onset latency of median sensory nerve action potential (SDL) is measured at $14 \mathrm{~cm}$, and the amplitude of the sensory nerve action potential (MSA) is measured from baseline to the negative peak. The latency difference over $14 \mathrm{~cm}$ between antidromically obtained median/ulnar sensory action potentials (SNAP) is studied over ring finger.

\section{Inclusion criteria:}

Hundred and thirty symptomatic hands from 106 patients fulfilled the following study inclusion criteria -: 
a) The presence of sensory symptoms in hand/s, persisting for $\geq 4$ weeks prior to the NCS evaluation. The symptoms were required to involve one or more of lateral three fingers and also either nocturnal appearance or precipitation/aggravation by any maneuvers leading to median nerve compression at wrist; plus

b) One of the above-mentioned NCS abnormalities.

\section{Exclusion criteria:}

Patients $(n=104)$ with following conditions were excluded a) history suggestive of cervical radiculopathies, b) trauma to the symptomatic limb, c) diabetes with symptoms or NCS findings suggestive of peripheral neuropathy, d) received invasive treatment (local steroid injections or surgery), e) history of arthritis, f) changed contact details e) normal NCS findings, and f) refusal to participate in the study.

\section{Results}

Table 1: Patient related variables

\begin{tabular}{|c|c|c|c|c|c|}
\hline Variables & $\begin{array}{l}\text { Remission } \\
\text { n (percent) }\end{array}$ & No remission $n$ (percent) & & \multicolumn{2}{|l|}{$\begin{array}{l}\text { Statistical analysis } \\
\text { OR }\left(95 \% \text { CI }{ }^{*}\right.\end{array}$} \\
\hline Total hands $(n=130)$ & $60(46.1)$ & $70(53.9)$ & & & \\
\hline \multicolumn{6}{|l|}{ Gender } \\
\hline Female $(\mathrm{n}=95,73 \%)$ & $45(47.3)$ & $50(52.6)$ & & $\begin{array}{l}\text { OR 1.20 } \\
(0.5-2.62)\end{array}$ & \\
\hline \multicolumn{6}{|c|}{$\begin{array}{l}\text { The number of symptomatic hands was more in females }(73 \text { vs. } 27 \%) \text { and persons with high BMI }(61.5 \text { vs. } 38.5) ; 27.7 \% \text { o } \\
\text { the hands belonged to the persons having concomitant medical issues. Female gender showed slightly higher odds (OR } 1.2 \\
\text { CI } 0.5-2.6 \text {, two-tailed } \mathrm{p}=0.5) \text { for remission on medical therapy. }\end{array}$} \\
\hline Variables & & $\begin{array}{l}\text { Remission } \\
\text { n (percent) }\end{array}$ & $\begin{array}{l}\text { No remission } \\
\mathbf{n} \text { (percent) }\end{array}$ & $\operatorname{OR}(95 \% \mathrm{CI})^{*}$ & p value \\
\hline Duration of symptoms (months) & $\begin{array}{l}\leq 10(\mathrm{n}=41,31.5 \%) \\
>10(\mathrm{n}=89,68.5 \%)\end{array}$ & $\begin{array}{l}33(80.4) \\
27(30.3)\end{array}$ & $\begin{array}{l}8(19.6) \\
62(69.7)\end{array}$ & $\begin{array}{l}\text { OR 9.47 } \\
(3.8-23.1)\end{array}$ & $\begin{array}{l}\mathrm{p}=<0.0001 \\
(\mathrm{~s})^{\dagger}\end{array}$ \\
\hline
\end{tabular}

The median duration of symptoms of our study population was12 months (mean 24.16 \pm 28.93 months). We had 40 patients having CTS in bilateral hands $(\mathrm{n}=80$ hands), while 50 patients had unilateral hand symptoms $(n=50$ hands $)$. Forty-one $(31.5 \%)$ hands were symptomatic for 10 months or less (median 6 months) while remaining 89 hands were symptomatic for longer than 10 months (median 24 months). Shorter duration of the symptoms, at presentation, had significant higher odds of spontaneous remission (OR 9.47 CI 3.8-23.1, two-tailed $\mathrm{p}=<0.0001$ ).

Table 3: NCS related variables

\begin{tabular}{llll}
\hline Median MDL $(\mathbf{m s})$ & & & \\
\hline$\leq 5.9(\mathrm{n}=74,56.9 \%)$ & $39(52.7)$ & $35(47.2)$ & OR 1.85 \\
& & & $(0.9-3.7)$ \\
\hline
\end{tabular}

\section{Discussion}

As reported previously ${ }^{[5]}$ we too found a preponderance of hands belonging to female gender (73\% vs. 27\%) and the persons with high BMI (61.5\% vs. 38.5\%). Previous work reports that female sex, male sex, overweight, the age beyond 50 years ${ }^{[6,7]}$ presence of concomitant illness respond poorly to conservative therapy. In our study, $46.1 \%$ of the hands with CTS achieved spontaneous symptoms remission on medical treatment. These findings are in line with that of DeStefano et al, who report improvement on conservative treatment in $52 \%$ of their patients ${ }^{[8]}$. Attempts to identify prognostic factors associated with a good outcome of medically treated patients have been made previously.A multiperspective study found young age to be associated with spontaneous remissions ${ }^{[9]}$.

Our results indicate that female gender, duration of $<10$ months, MDL $<5.9 \mathrm{~ms}$, MSA $>20 \mu \mathrm{V}$, SDL of $<3.4 \mathrm{~ms}$, symptoms restricted to lateral three fingers and Bland's grade 1-3 are associated with higher odds of spontaneous remission.

\section{Conclusion}

In conclusion, it seems reasonable to treat subjects of CTS, conservatively for first ten months after symptom onset, more so when they have four or more out of the seven favorable factors.

\section{References}

1. Padua L, Coraci D, Erra C, Pazzaglia C, Paolasso I, Loreti C, Caliandro P, Hobson-Webb LD. Carpal tunnel syndrome: clinical features, diagnosis, and management. The Lancet Neurology. 2016 Nov $1 ; 15(12): 1273-84$.

2. Chammas M, Boretto J, Burmann LM, Ramos RM, Neto FCS, Silva JB. Carpal tunnel syndrome - part 1 (anatomy, physiology, etiology and diagnosis). Revista brasileira de Ortopedia (English edition) 2014 September-October; 49 (5):429-436. 
3. Bickel KD. Carpal tunnel syndrome. J Hand Surg Am2010;35(01): 147-152.

4. Kimura J. Electrodiagnosis in diseases of nerve and muscle:principles and practice. Philadelphia: FA Davis.1983:106-11.

5. Lam N, Thurston A. Association of obesity, gender, age and occupation with carpal tunnel syndrome. Aust N Z J Surg.1998;68(3):190-193.

6. Bland JDP, Rudolfer SM. Clinical surveillance of carpal tunnel syndrome in two areas of the United Kingdom.

NeurolNeurosurgPsychiatry.2003;74:1674-1679.
7. Becker J, Nora DB, Gomes I, Stringari FF, Seitensus R, Panosso JS, et al. An evaluation of gender, obesity, age and diabetes mellitus as risk factors for carpal tunnel

syndrome.ClinicalNeurophysiology.2002;113(9):1429 $-1434$.

8. DeStefano F, Nordstrom DL, Vierkant RA. Long-term symptom outcomes of carpal tunnel syndrome and its treatment.J Hand Surg.1997;221:200-210.

9. Padua L, Padua R, Aprile I, Pasqualetti P, Tonali P. Multiperspective follow-up of untreated carpal tunnel syndrome.Neurology.2001;56:1459-1466. 